\title{
Evaluation of soil thermal diffusivity algorithms at two equatorial sites in West Africa
}

\author{
Taofeek Abiodun Otunla ${ }^{\star}$, Ezekiel Oluyemi Oladiran
}

University of Ibadan, Department of Physics, Ibadan, Nigeria

\author{
Article history \\ Received July 7, 2011; accepted August 2, 2012. \\ Subject classification: \\ Processes and Dynamics, Thermal diffusivity, soil temperature, soil moisture content, West Africa.
}

\begin{abstract}
This study presents comparisons between six algorithms used in the calculation of apparent thermal diffusivity $\left(K_{h}\right)$ of the topsoil during measurement campaigns conducted at two equatorial sites. It further investigates the effects of transient and seasonal variations in soil moisture content $(\theta)$ on the estimation of $K_{h}$. The data used comprise soil temperatures $(T)$ measured at depths of $0.05 \mathrm{~m}$ and $0.10 \mathrm{~m}$, and $\theta$ within the period of transition from the dry season to the wet season at Ile Ife $\left(7.55^{\circ} \mathrm{N}\right.$, $\left.4.55^{\circ} \mathrm{E}\right)$, and for the peak of the wet season at Ibadan $\left(7.44^{\circ} \mathrm{N}, 3.90^{\circ} \mathrm{E}\right)$. The thermal diffusivity, $K_{h}$, was calculated from six algorithms, of: harmonic, arctangent, logarithmic, amplitude, phase, and conduction-convection. The reliability of these algorithms was tested using their values to model $T$ at a depth of $0.10 \mathrm{~m}$, where direct measurements were available. The algorithms were further evaluated with statistical indices, including the empirical probability distribution function of the differences between the measured and modeled temperatures $(\Delta T)$. The maximum absolute values of $\Delta \mathrm{T}$ for the six algorithms investigated were: $0.5^{\circ} \mathrm{C}$, $0.5^{\circ} \mathrm{C}, 0.5^{\circ} \mathrm{C}, 1^{\circ} \mathrm{C}, 1^{\circ} \mathrm{C}$ and $1^{\circ} \mathrm{C}$, respectively. $K_{h}$ showed an increasing trend as $\theta$ increased from the dry season to the peak of the wet season, with $R^{2}=0.70$ for the harmonic algorithm. The accuracy of all of the algorithms in modeling $T$ reduced with transient variations of $\theta$. The harmonic, arctangent and logarithmic algorithms were the most appropriate for calculating $K_{h}$ for the region of study. The empirical relation between $\theta$ and $K_{h}$ and the values of $K_{h}$ obtained in this study can be used to improve the accuracy of meteorological and hydrological models.
\end{abstract}

\section{Introduction}

In recent times, there have been concerted efforts to understand the impact of the surface-atmosphere interactions of the Earth on the weather and climate of West Africa through coupling Earth surface models with regional climate models [Steiner et al. 2009, Taylor et al. 2011]. Direct measurements of the processes that govern these interactions are very important, to improve the accuracy of their representations in the models. The equation of conservation of energy of these processes at the Earth surface is given as [Foken 2008]:

$$
R_{n}=H+L E+G
$$

where, $R_{n}$ is the net radiation, $G$ is the soil heat flux, and $H$ and $L E$ are the sensible and latent heat fluxes, respectively.

The soil heat flux $(G)$ in particular is a very important component of Equation (1) for measurements taken over dry, bare surfaces, such as during the night or immediately after sunrise, and it can account for up to $40 \%$ of $R_{n}$ [Verhoef et al. 1996, 2004]. The determination of $G$ requires a realistic understanding of the soil thermal properties; i.e., the soil heat capacity $\left(C_{h}\right)$ and the thermal diffusivity $\left(K_{h}\right)$. According to Sellers [1965] and Foken [2008], the method for estimation of $C_{h}$ is stable and well established. Therefore, the optimum estimation of $K_{h}$ will improve the accuracy of $G$. In addition, the thermal diffusivity, $K_{h}$, has an important role in the determination of soil temperature $(T)$ propagation because it determines the heating or cooling rate that accompanies a given temperature profile [Sellers 1965, Oke 1978, Zhang and Osterkamp 1995]. Apart from the estimation of $G$ and the determination of the $T$ propagation, accurate modeling of turbulent heat fluxes using resistance methods also requires realistic knowledge of $K_{h}$, the soil moisture content $(\theta)$, and $T$ of the soil being investigated [Stensrud 2007].

The starting point for the derivation of the thermal diffusivity algorithm is based on the solution of the one-dimensional conduction heat transfer equation. A basic requirement of the assumed wave-like solution is that parameter $K_{h}$ in the heat conduction equation is constant with depth. However, in experimental determination of this parameter, variations in $K_{h}$ are possible due to changes in soil type and moisture content with depth. A depth of $\leq 0.10 \mathrm{~m}$ is often used to eliminate the variation in $K_{h}$ due to soil type. It is believed that the soil type is not likely to have changed over such a small depth.

If the temperature of the upper layer is modeled using a Fourier series to accurately describe the variations in soil temperature in that layer [Van Wijk and De Vries 1963], the 
analytical solution of the one-dimensional heat conduction equation can be used to estimate $K_{h}$. Based on this solution, $K_{h}$ can be estimated by the harmonic, arctangent, logarithmic, amplitude, and phase algorithms. The arctangent and logarithmic algorithms use two harmonics [Nerpin and Chudnovskil 1967, Seemann 1979], while the amplitude and phase algorithms are based on the assumption of a single sinusoidal temperature wave [Sellers 1965]. Errors due to the assumption of a sinusoidal function for temperature propagation in the soil reduce as the number of harmonics increases. Horton et al. [1983] used least-squares difference between the measured and calculated temperatures to select a value of $K_{h}$ (this method is hereafter referred to as the harmonic method). This harmonic method has the advantage of using a series of harmonics to accurately describe the surface temperature.

All of the algorithms presented above are based on the solution of the one-dimensional heat conduction equation and the assumption of constant $K_{h}$. From two experiments, one in a temperate region (Spain, $2^{\circ} 55^{\prime} 48^{\prime \prime} \mathrm{N}, 39^{\circ} 08^{\prime} 30^{\prime \prime} \mathrm{E}$ ) and the other in the Sahel $\left(13^{\circ} 32^{\prime} 60^{\prime \prime} \mathrm{N}, 2^{\circ} 30^{\prime} 68^{\prime \prime} \mathrm{E}\right)$, Verhoef et al. [1996] showed that $K_{h}$ is related to soil moisture content (and is thus related to rainfall). This result indicated that the assumption of constant $K_{h}$ will not be correct for some climate conditions, even when the soil type is homogeneous with depth. It would therefore be desirable to replace the one-dimensional heat conduction equation with another that can account for the variation in $K_{h}$ by coupling the heat transfer by the flux of moisture with the conduction process. Gao et al. [2003] proposed an algorithm for the calculation of $K_{h}$ that accounted for vertical variations in $K_{h}$ in heat transfer processes by coupling the conduction and convection processes in the soil.

An alternative approach is to establish an empirical relationship between the various algorithms used in the estimation of $K_{h}$ and soil moisture content $(\theta)$. One of the objectives of the present study was therefore to investigate the effects of seasonal and transient variations in $\theta$ on $K_{h}$, with a view to establishing an empirical relationship between these two parameters. Another objective was to evaluate six thermal diffusivity algorithms to determine the appropriate ones for the estimation of $K_{h}$ for two equatorial sites. With these two objectives, the study aimed to obtain a more accurate representation of the soil thermal dynamics in the meteorological and hydrological models used for the region of study.

\section{Theoretical background}

The one-dimensional conduction heat transfer equation in an isotropic medium is given by:

$$
\frac{\partial T}{\partial t}=K_{h} \frac{\partial^{2} T}{\partial z^{2}}
$$

where, $K_{h}$ is independent of depth and time.
Using the Fourier series representation [Van Wijk and De Vries 1963], the soil temperature near the surface can be described accurately by:

$$
T(t)=\bar{T}+\sum_{k=1}^{N} C_{k} \operatorname{Cos}\left(k \omega t-\phi_{k}\right)
$$

where $C_{k}=\left[A_{k}^{2}+B_{k}^{2}\right]^{\frac{1}{2}}, A_{k}$ and $B_{k}$ are the amplitudes of the kth harmonic of the temperature wave, $\bar{T}$ is the mean soil temperature, $\omega$ is the angular velocity of the Earth rotation, $\omega=2 \pi / P$, where $P$ is the period of the diurnal cycle, $N$ is the number of harmonics, and $\phi_{k}$ is the phase angle, where

$$
\phi_{k}\left[\begin{array}{ll}
\tan ^{-1} & \left(B_{k} / A_{k}\right) A_{k}>0 \\
\tan ^{-1} & \left(B_{k} / A_{k}\right) \pm \pi
\end{array} A_{k}<0\right.
$$

Based on the analytical solutions of Equation (2) through applying Equation (3), the amplitude and phase algorithms that assume a single sinusoidal temperature wave function (i.e., by setting $N$ to 1 in Equation 3) were respectively obtained as:

$$
K_{h}=\frac{\pi}{P}\left[\frac{z_{1}-z_{2}}{\ln \left[C_{1} / C_{2}\right]}\right)^{2}
$$

and

$$
K_{h}=\frac{\pi}{P}\left[\frac{z_{1}-z_{2}}{\phi_{1}-\phi_{2}}\right]^{2}
$$

where, $C_{1}$ and $C_{2}$ are the amplitudes, and $\phi_{1}$ and $\phi_{2}$ are the initial phases of the soil temperature at the depths of $z_{1}$ and $z_{2}$, respectively.

The arctangent and logarithmic algorithms, which use two harmonics in the temperature wave Equation (3) [Nerpin and Chudnovskil 1967, Seemann 1979], were also obtained as:

$$
\begin{aligned}
& K_{h}= \\
& P\left\{\arctan \left[\frac{\left(T_{1}-T_{3}\right)\left(T_{2}^{\prime}-T_{4}^{\prime}\right)-\left(T_{2}-T_{4}\right)\left(T_{1}^{\prime}-T_{3}^{\prime}\right)}{\left(T_{1}-T_{3}\right)\left(T_{1}^{\prime}-T_{4}^{\prime}\right)+\left(T_{2}-T_{4}\right)\left(T_{2}^{\prime}-T_{4}^{\prime}\right)}\right]\right\}
\end{aligned}
$$

and

$$
K_{h}=\left[\frac{0.0121\left(z_{2}-z_{1}\right)}{\ln \left[\frac{\left(T_{1}-T_{3}\right)^{2}+\left(T_{2}-T_{4}\right)^{2}}{\left(T_{1}^{\prime}-T_{3}^{\prime}\right)^{2}+\left(T_{2}^{\prime}-T_{4}^{\prime}\right)^{2}}\right]}\right]^{2}
$$

respectively. Temperatures $T_{i}$ and $T_{i}^{\prime}$ are recorded every $6 \mathrm{~h}$ (i.e., subscripts 1 to 4 ) at the two depths of $z_{1}$ and $z_{2}$, respectively.

Horton et al. [1983] used least-squares differences between the measured and calculated $T$ to select a value of $K_{h}$ through iteration at the required depth. The method used in Equation (8) below is an analytical solution to Equation (2) 
that uses the boundary conditions in Equation (3) to calculate the soil temperature at the required depth:

$$
\begin{aligned}
& T(z, t)= \\
& \bar{T}+\sum_{k=1}^{N}\left\{C_{o k} e^{-z \sqrt{k \omega / 2 K_{h}}} \operatorname{Cos}\left(k \omega t-\phi_{o k}-z \sqrt{k \omega / 2 K_{h}}\right)\right\}
\end{aligned}
$$

where $C_{o k}$ and $\phi_{o k}$ are the amplitude and phase angle of the kth harmonic for the upper boundary, respectively [Horton et al 1983, Caslaw and Jaeger 1959, Van Wijk and De Vries 1963]. Equations (2) and (8) are slightly different from those proposed by the aforementioned studies, in that while they proposed a sine function, an equivalent cosine function with the appropriate transformation of the phase angle defined in Equation (3) can be used.

To account for the variation in $K_{h}$ with depth due to changes in the moisture content in the heat transfer equation in the soil, Gao et al. [2003] coupled the thermal conduction and convection processes together as:

$$
\frac{\partial T}{\partial t}=K_{h} \frac{\partial^{2} T}{\partial z^{2}}+w \frac{\partial T}{\partial z}
$$

where, $w$ represents the net water flow from a layer of soil at a given depth. With the boundary condition set at the lower depth $z_{2}$ that is modeled by a sinusoidal function as $T_{z=z_{2}}=$ $\bar{T}_{2}+A_{2} \cos \left(\omega t+\phi_{2}\right)$, the expression of the soil temperature at the upper depth is given by:

$T(z, t)=$

$\bar{T}_{1}+A_{2} \exp \left\{-K_{h}\left(z_{1}-z_{2}\right) M\right\} \operatorname{Cos}\left\{\omega t+\phi_{2}-K_{h}\left(z_{1}-z_{2}\right) N\right\}$

where:

$$
\begin{gathered}
M=\frac{K_{h}}{\omega}\left[w+\frac{1}{\sqrt{2}}\left[w^{2}+\left(w^{4}+\frac{4 \omega^{4}}{k_{h}^{4}}\right)^{1 / 2}\right]\right] \text { and } \\
N=\sqrt{2}\left[\frac{\omega}{k_{h}}\right]\left[w^{2}+\left[w^{4}+\frac{4 \omega^{4}}{k_{h}^{4}}\right]^{1 / 2}\right]^{-1 / 2}
\end{gathered}
$$

The expressions for $K_{h}$ and $w$ are then obtained from Gao et al. [2003] and Gao et al. [2007] as:

$$
K_{h}=-\frac{\left(z_{1}-z_{2}\right)^{2} \omega \ln \left(A_{1} / A_{2}\right)}{\left(\phi_{1}-\phi_{2}\right)\left[\left(\phi_{1}-\phi_{2}\right)^{2}+\ln ^{2}\left(A_{1} / A_{2}\right)\right]}
$$

and

$$
w=\frac{\omega\left(z_{1}-z_{2}\right)}{\phi_{1}-\phi_{2}}\left[\frac{2 \ln ^{2}\left(A_{1} / A_{2}\right)}{\left(\phi_{1}-\phi_{2}\right)^{2}+\ln ^{2}\left(A_{1} / A_{2}\right)}-1\right] .
$$

\section{Materials and methods}

\subsection{Climate of the region}

The sites used in this study are located in a humid equatorial region of West Africa where the climate is classified as
Aw according to the Köppen system [Essenwager 2003]. This implies a tropical region with a dry winter season and a wet summer season. This change in season occurs in association with the meridional movement of the inter-tropical discontinuity (ITD) line across West Africa [Adedokun 1978, Otunla et al. 2008]. The ITD line defines the region of the meeting of the dry, dust-laden, north-easterly wind (the harmattan wind) and the moist, warm, south-westerly wind coming from the Atlantic Ocean (the monsoonal wind). The region of West Africa that is south of the ITD at any given time is in the wet season, while the region that is north of the ITD is in the dry season. For the region of West Africa used in the present study, each year is roughly divided into two: the wet or rainy season (April to October), and the dry season (November to March). In addition to the convective activities that occur during the transition period (usually between February and March), these two wind regimes define the prevalent weather conditions that characterized the climate of the region. The mean annual rainfall and the maximum and minimum temperatures for the region where these two sites are located are $1225 \mathrm{~mm}, 42^{\circ} \mathrm{C}$ and $15^{\circ} \mathrm{C}$, respectively. These values were obtained from 50 years of data from the meteorological stations in the neighbourhood of the measuring sites (within a minimum of a $150-\mathrm{km}$ radius). The stations are maintained by the Nigerian Meteorological Agency, which has measurement stations across the whole country. To have a wide spectrum of $\theta$ available for analysis in the present study, two separate time series within the year were selected, to capture the peaks of the two recurring seasons in the region.

\subsection{Experimental sites and measurements}

Within the framework of the Nigerian Micrometeorology Experiment [Jegede et al. 2004], an experiment was conducted at Ile-Ife, Nigeria $\left(7.55^{\circ} \mathrm{N}, 4.55^{\circ} \mathrm{E}\right)$, during the transition from the dry to the wet season. The period of intensive observation was from February 19, 2004, through to March 9, 2004 (days of the year [DOYs] 55 to 68). The three prevalent weather conditions that characterized the climate of the region were observed at this site during the measurements [Mauder et al. 2007]. The maximum and minimum temperatures (Tmax, Tmin, respectively) at the soil depth of $0.05 \mathrm{~m}$, and the total rainfall during the period of the experiment, are shown in Figure 1. The altitude of the site is $288 \mathrm{~m}$ above sea level, and its vegetation can be characterized as fallow bush-land with $0.30-\mathrm{m}$ canopy height. The ground surface of the site was flat and homogenous at the time of the measurements. The soil texture was loamy sand, and it was at its permanent wilting condition at the beginning of the experiments [Jegede et al. 2004, Mauder et al. 2007]. The period of the experiments was selected to investigate the soil thermal dynamics from the time when the soil was nearly completely desiccated to when it was slightly wet with rainfall. 


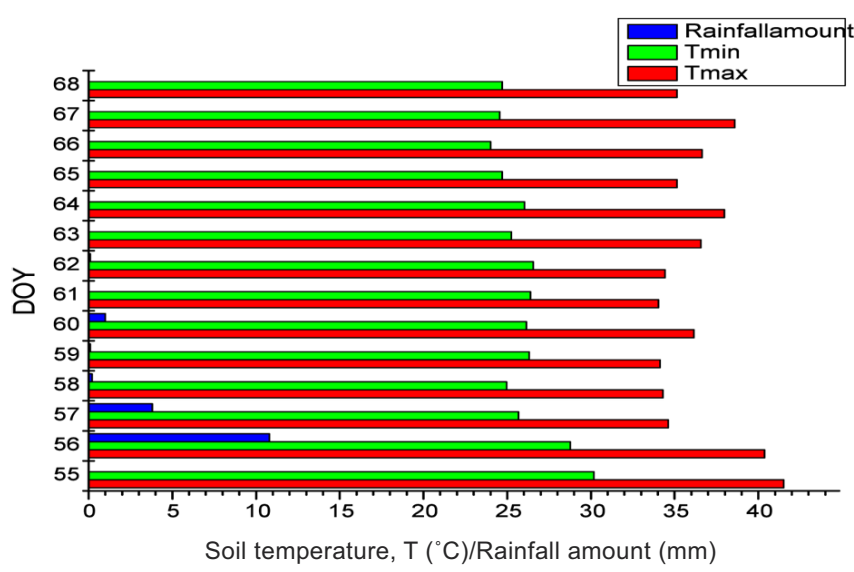

Figure 1. Temporal variations of maximum temperature (Tmax.), minimum temperature (Tmin.) and rainfall amount at Ile Ife site from DOY 55 to DOY 68, 2004.

Another phase of the Nigerian Micrometeorology Experiment was carried out at Ibadan in the experimental field of the Lower Atmospheric Physics Unit, University of Ibadan, Ibadan, Nigeria $\left(7.44^{\circ} \mathrm{N}, 3.90^{\circ} \mathrm{E}\right)$. Twelve days of continuous measurements at this site were used in this study (June 3, 2006, to June 15, 2006), to capture the soil thermal dynamics at the time when the soil was nearly saturated with moisture induced by persistent rainfall, which usually characterizes this time of the year. The site is located at about 78 $\mathrm{km}$ from Ile Ife, and it comprises of an area of $850 \mathrm{~m}^{2}$ of flat terrain at an elevation of $220 \mathrm{~m}$ above sea level. The soil type is loamy sand, and the ground surface of the target area was bare at the time of the measurements. The Tmax and Tmin at the soil depth of $0.05 \mathrm{~m}$ and the rainfall during the period of the experiments are shown in Figure 2.

At the two sites, $T$ was measured with two soil thermocouple probes (Campbell Scientific Inc., USA) buried at the depths of $0.05 \mathrm{~m}$ and $0.10 \mathrm{~m}$. The moisture content $(\theta)$ of the soils was measured between the surface and $0.05 \mathrm{~m}$ in depth using soil moisture reflectometers (CS615, CS616, Campbell Scientific Inc., USA). These soil moisture reflectometers were installed in such a way that the ground surface wetness due to rainfall occurrence could be measured to the depth of $0.05 \mathrm{~m}$ and even deeper. This was necessary to account for the heterogeneity in $K_{h}$ induced by $\theta$. The rainfall was measured using an ARG100 Rainguage (Campbell Scientific Inc., USA). These sensors were controlled by using a Campbell CR10X datalogger, which sampled the data every $1 \mathrm{~s}$, and then stored these data as 1-min-averaged values.

The soil temperature $(T)$ at the depths of $0.05 \mathrm{~m}$ and $0.10 \mathrm{~m}$ obtained from the two sites were smoothed using 2 -h averaging to calculate $C_{1}, C_{2}, \phi_{1}, \phi_{2}, \bar{T}_{1}, \bar{T}_{2}, \bar{T}, C_{k}$ and $\phi_{k}$ from Fourier analysis of the time series for each day. The values of these variables were used in Equations (3) and (8) to model $T$ at the two depths, and also in Equations (4), (5) and (8) to calculate $K_{h}$ for the harmonic, amplitude, and phase algorithms. The calculated values of $K_{h}$ using the arctangent and logarithmic algorithms (Equations 6,7) were sensitive to

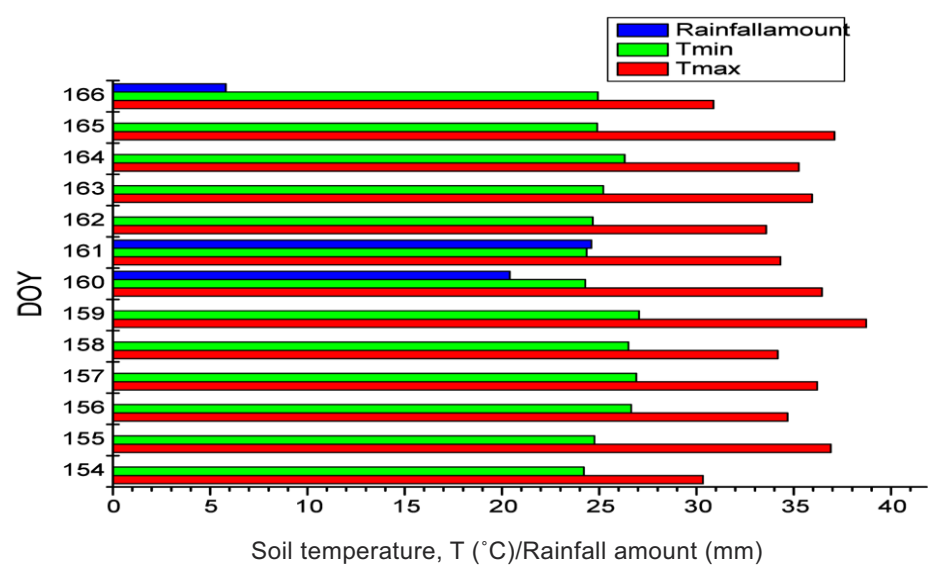

Figure 2. Temporal variations of maximum temperature (Tmax.), minimum temperature (Tmin.) and rainfall amount at Ibadan site from DOY 55 to DOY 68, 2004.

the measurement times of the four pairs of $T$ at each depth, so the calculated values of $K_{h}$ from three different selections of four temperature values were averaged to obtain a more representative value of $K_{h}$. Both $K_{h}$ and the net water flow, $w$, were calculated for the conduction-convection algorithm using Equations (12) and (13).

\subsection{Data analysis methods}

The predicted soil temperatures from the six thermal diffusivity algorithms and the measured soil temperatures were compared using regression analysis. The performances of the algorithms were also evaluated using the following statistical indices and measures of errors:

1. The coefficient of determination $\left(R^{2}\right)$, which indicates the precision of the modeled soil temperature in relation to the measured values.

2. The agreement index (D), which indicates the accuracy of the modeled soil temperature in relation to the measured values [Willmott et al. 1985], and is given by:

$$
D=1.0-\left\{\frac{\sum\left(M_{i}-P_{i}\right)}{\sum\left(\left|P_{i}-M_{a}\right|+\left|M_{i}-M_{a}\right|\right)^{2}}\right\}
$$

where, $P_{i}$ is the predicted temperature, $M_{i}$ is the measured temperature, $M_{a}$ is the average of the measured temperatures. The index ranges from 0 (without agreement) to 1 (perfect agreement).

3. The confidence index C [Camargo and Sentelhas 1997] was also used. This index is obtained by multiplying together $\mathrm{D}$, a measure of the accuracy, and the correlation coefficient $(\mathrm{r})$, a measurement of the precision. The $\mathrm{C}$ values range from 0 , for poor confidence, to 1 , for very good confidence.

4. Standard deviation of the mean (or root-mean-square error), SE, and normalized standard deviation of the mean, NSE (i.e., an estimate of relative uncertainty), were used to assess the error of the model output, where: 
a)

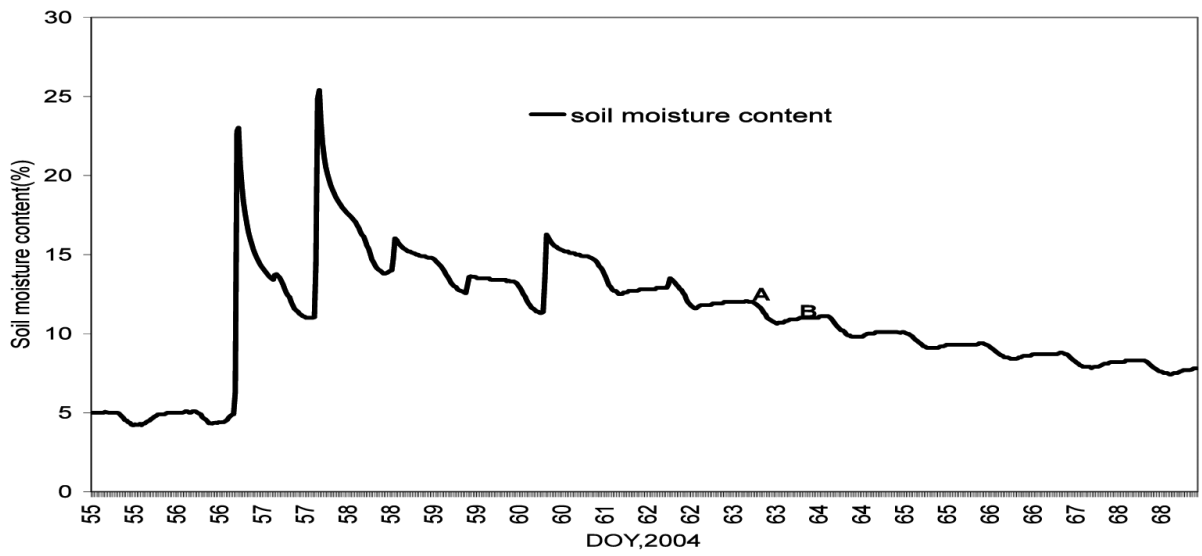

b)

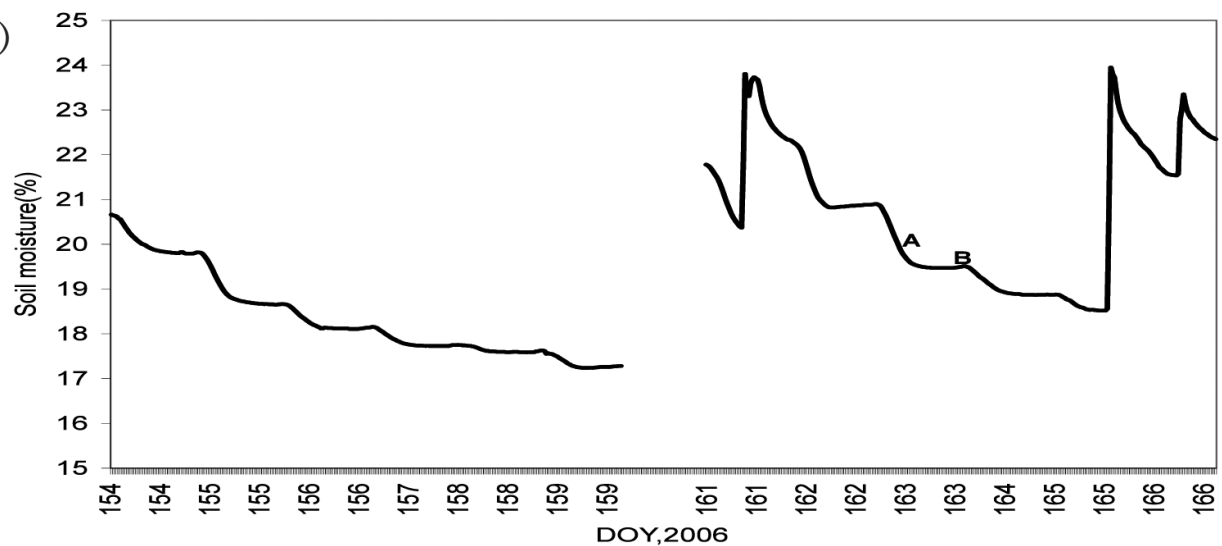

Figure 3. Temporal variations of soil water content (\%) measured at depth of 0-0.05 m at (a) Ile Ife site from DOY 55 to DOY 68,2004 and (b) Ibadan site from DOY 154 to $166,2006$.

$$
\mathrm{SE}=\sqrt{\frac{\sum_{i=1}^{n}\left(P_{i}-M_{i}\right)^{2}}{n-2}}
$$

and

$$
\mathrm{NSE}=\sqrt{\frac{\sum_{i=1}^{n}\left(P_{i}-M_{i}\right)^{2}}{\sum_{i=1}^{n} M_{i}^{2}}}
$$

5. Finally, another comparison of the accuracies of the algorithms is given by the empirical probability distribution functions (PDFs) [Taylor 1982] of the difference between the predicted and measured soil temperatures, $\Delta T$, at the soil depth of $0.10 \mathrm{~m}$.

\section{Results and discussion}

\subsection{Soil moisture content}

\subsubsection{The Ile Ife site}

At the beginning of the experiment at Ile Ife, after several weeks without precipitation during the dry season, the soil at the site was desiccated. The soil moisture content $(\theta)$ was measured at $5 \%$ (Figure 3a). This corresponds to the permanent wilting point of the on-site loamy sand [Boden 1994]. The total rainfall during the period of measurement was $16.2 \mathrm{~mm}$ (Figure 1). The temporal variation of $\theta$ be- tween the surface and $0.05 \mathrm{~m}$ in depth at this site (Figure 3a) indicated that precipitation occurred on DOYs 56 and 57. Owing to evaporation from the soil surface, the $\theta$ then decreased gradually from DOY 57 to DOY 68, except for a slight increase on DOY 60.

\subsubsection{The Ibadan site}

The temporal variation in $\theta$ between the surface and $0.05 \mathrm{~m}$ in depth at the Ibadan site is shown in Figure 3b. The rainfall at this site from DOYs 150 to 153 was $0.9 \mathrm{~mm}$, while the rainfall on DOY 161 and DOY 165 were $24.6 \mathrm{~mm}$ and 20.4 $\mathrm{mm}$, respectively (Figure 2 ). The soil moisture content, $\theta$, decreased gradually from DOY 153 to DOY 159, and from DOY 161 to DOY 164 , due to evaporation from the soil surface and/or percolation into the subsurface (Figure 3b).

Figure $3 \mathrm{a}, \mathrm{b}$ also shows that the diurnal variations of the soil moisture content were superimposed on the temporal variations (A and B in Figure 3a, b show examples of such diurnal variations).

\subsection{Thermal diffusivity}

\subsubsection{The Ile Ife site}

The smallest value of $K_{h}$ was $2.47 \times 10^{-7} \mathrm{~m}^{2} \mathrm{~s}^{-1}$, which was obtained from the amplitude algorithm on DOY 57 , while the maximum was $8.42 \times 10^{-7} \mathrm{~m}^{2} \mathrm{~s}^{-1}$, as obtained 


\begin{tabular}{|c|c|c|c|}
\hline \multirow[t]{2}{*}{ Site } & \multicolumn{3}{|c|}{$K_{h}$} \\
\hline & $\begin{array}{c}\text { Mean } \\
\left(\times 10^{7} \mathrm{~m}^{2} / \mathrm{s}\right)\end{array}$ & $\begin{array}{c}\text { Maximum } \\
\left(\times 10^{7} \mathrm{~m}^{2} / \mathrm{s}\right)\end{array}$ & $\begin{array}{c}\text { Min } \\
\left(\times 10^{7} \mathrm{~m}^{2} / \mathrm{s}\right)\end{array}$ \\
\hline \multicolumn{4}{|c|}{ Harmonic algorithm } \\
\hline Ile Ife & 5.46 & 6.24 & 4.48 \\
\hline Ibadan & 8.50 & 20.70 & 5.96 \\
\hline \multicolumn{4}{|c|}{ Arctangent algorithm } \\
\hline Ile Ife & 6.58 & 8.42 & 5.00 \\
\hline Ibadan & 10.20 & 22.30 & 5.45 \\
\hline \multicolumn{4}{|c|}{ Logarithmic algorithm } \\
\hline Ile Ife & 4.83 & 6.13 & 2.73 \\
\hline Ibadan & 7.26 & 8.77 & 5.95 \\
\hline \multicolumn{4}{|c|}{ Amplitude algorithm } \\
\hline Ile Ife & 4.49 & 5.81 & 2.47 \\
\hline Ibadan & 8.19 & 11.00 & 5.64 \\
\hline \multicolumn{4}{|c|}{ Phase algorithm } \\
\hline Ile Ife & 5.93 & 7.48 & 4.10 \\
\hline Ibadan & 8.78 & 16.20 & 5.09 \\
\hline \multicolumn{4}{|c|}{ Conduction-convection algorithm } \\
\hline Ile Ife & 5.91 & 7.44 & 4.00 \\
\hline Ibadan & 8.13 & 14.40 & 3.64 \\
\hline
\end{tabular}

Table 1. The maximum, minimum and mean values of $K_{h}$ calculated according to the six algorithms for the soil layer of $0.05 \mathrm{~m}$ to $0.10 \mathrm{~m}$ at the Ile Ife and Ibadan sites.

\begin{tabular}{lc}
\hline DOY & $\begin{array}{c}\boldsymbol{w} \\
\left(\times 10^{6} \mathrm{~m} / \mathrm{s}\right)\end{array}$ \\
\hline 55 & 1.45 \\
56 & 2.12 \\
57 & 1.58 \\
58 & 1.35 \\
59 & 1.53 \\
60 & 1.39 \\
61 & 0.66 \\
62 & 1.72 \\
63 & 1.27 \\
64 & 1.21 \\
65 & 0.49 \\
66 & 0.69 \\
67 & 1.92 \\
68 & 1.09 \\
\hline
\end{tabular}

Table 2. The values of $w$ calculated by the conduction-convection algorithm for the soil layer of $0.05 \mathrm{~m}$ to $0.10 \mathrm{~m}$ at the Ile Ife site from DOY 55 to DOY 68, 2004. from the arctangent algorithm on DOY 63. The maximum, minimum and mean values of $K_{h}$ calculated for the six algorithms are listed in Table 1.

For the conduction-convection algorithm, another parameter $w$ was needed, which was calculated from Equation (13) (see Table 2). The values of this parameter indicated the net volumetric water flux from the layer of the soil between the surface and the depth of $0.05 \mathrm{~m}$. Its sign gives the direction of the water flux: a positive sign indicates an outward flux of water from the layer into the atmosphere, while a negative sign indicates an inward flux from the layer into the sub-surface soil [Gao et al. 2007]. As all of the values of $w$ were positive, this indicated evaporation from the soil layer. Under evaporation conditions, there is a net upward flux of water (liquid and vapor) as a result of the progressively dry surface conditions (Figure 3a). The net flux of water should be associated with net convective heat flux in the soil [Gao et al. 2008].

The reliability of the six algorithms was investigated by using them to predict $T$ at the depth of $0.10 \mathrm{~m}$ where direct measurements were also available for comparison. The measured and predicted $T$ at $0.10 \mathrm{~m}$ depth for DOYs 55 and 57 (the days selected to represent the dry and wet days, respectively) are given in Figure 4a, b. It should be noted that there was a significant amount of rainfall on DOYs 56 and 57 (Figure 1).

Two observations can be inferred from the visual inspection of Figure $4 \mathrm{a}, \mathrm{b}$. First, the measured $T$ was better fitted with the harmonic, arctangent and logarithmic algorithms, while the amplitude, phase and conduction-convection algorithms gave comparatively less accurate diurnal descriptions of $T$. Secondly, Figure $4 \mathrm{~b}$ shows that the wet day was poorly predicted compared with the dry day. The dataset was therefore divided into dry and wet days, to investigate the effects of transient heterogeneities such as rainfall and cloudiness on $K_{h}$. Efforts were made, however, to reduce the effects of transients to only the rainfall, by using 2 -h averaging. The dry days were DOY 55 and DOYs 61 to 68; the wet days were DOYs 56 to 60 .

These two separate datasets were subjected to six statistical analyses, to confirm the first observation (see Table 3 , for five of the six statistical analyses). The harmonic algorithm had the lowest values for SE and NSE, and the highest values for $\mathrm{R}^{2}$, $\mathrm{D}$ and $\mathrm{C}$. The arctangent and logarithmic algorithms had the second-lowest and third-lowest values for SE and NSE, respectively, and the second-highest and thirdhighest values for $\mathrm{R}^{2}, \mathrm{D}$ and $\mathrm{C}$, respectively.

To better quantify the deviations of the predicted $T$ from the measured values, an empirical PDF of the temperature deviation $(\Delta T)$ for all of the algorithms is shown in Figure $5 \mathrm{a}, \mathrm{b}$. The $\Delta \mathrm{T}$ for the dry days ranged from $-0.5{ }^{\circ} \mathrm{C}$ to $0.5^{\circ} \mathrm{C}$ for the harmonic, arctangent and logarithmic algorithms, with $94 \%$ to $99 \%$ data coverage; and it ranged 
a)

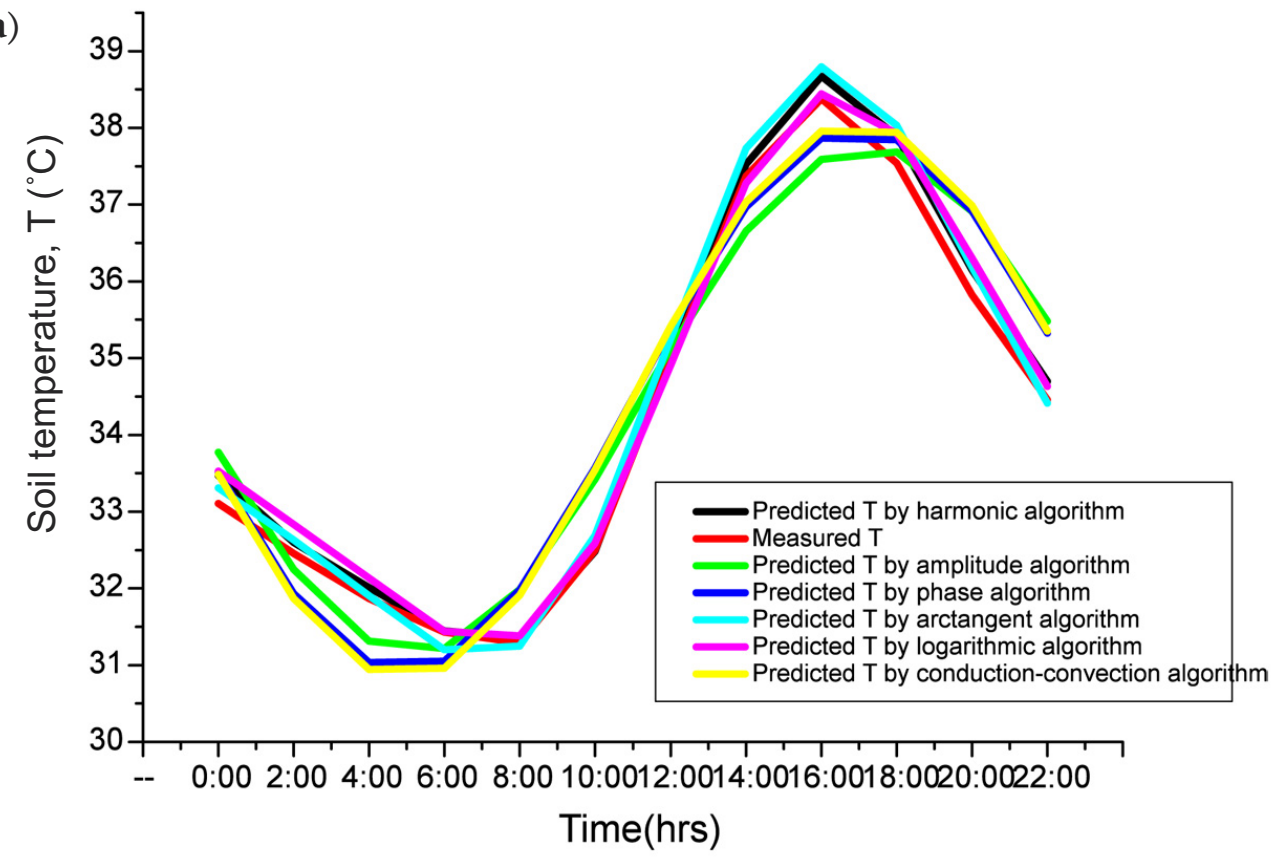

b)

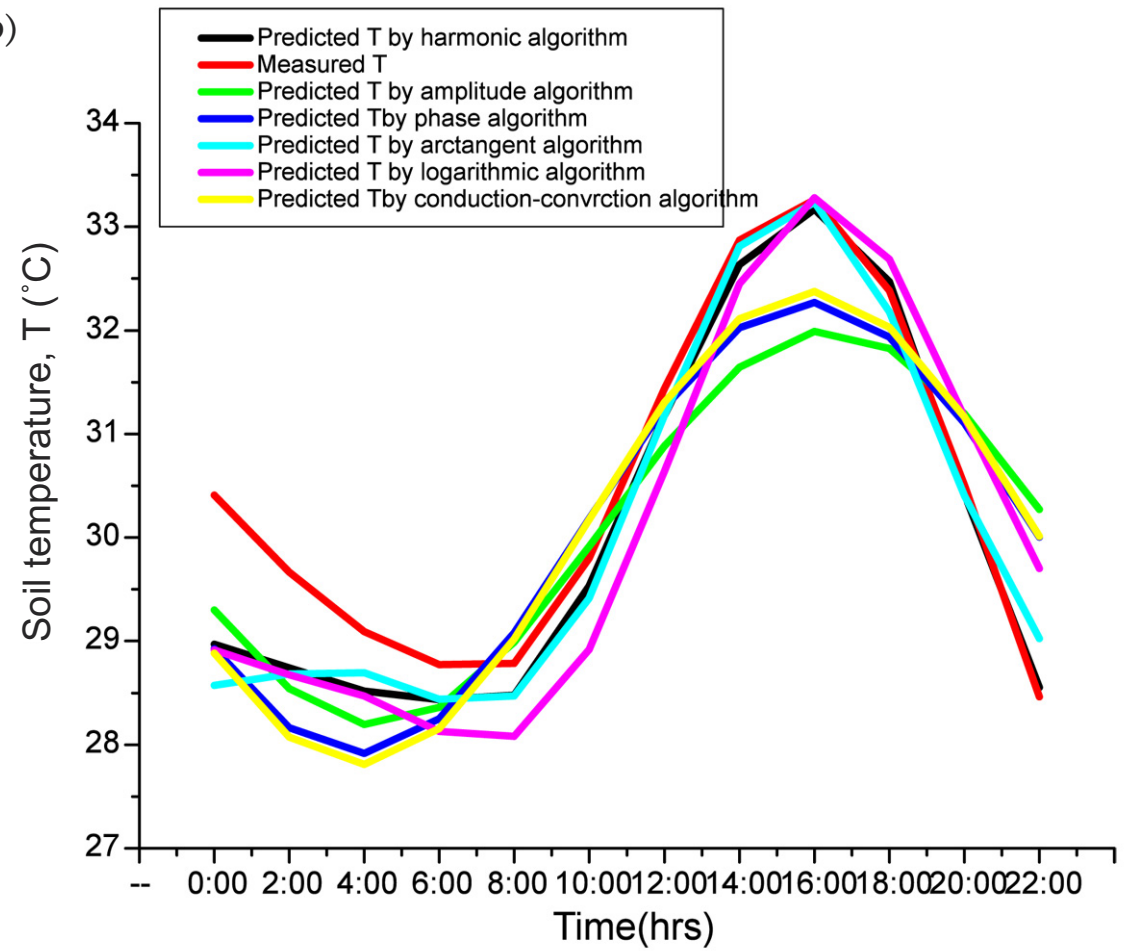

Figure 4. (a) Comparisons of soil temperature predicted by harmonic, arctangent, logarithmic, phase, amplitude and conduction-convection algorithm against measurements of soil temperature at $0.01 \mathrm{~m}$ depth at Ife site on DOY 55, 2004. (b) Comparisons of soil temperature predicted by harmonic, arctangent, logarithmic, phase, amplitude and conduction-convection algorithm against measurements of soil temperature at $0.01 \mathrm{~m}$ depth at Ife site on DOY 57, 2004.

from $-1{ }^{\circ} \mathrm{C}$ to $1{ }^{\circ} \mathrm{C}$ for the amplitude, phase and conductionconvection algorithms, with $93 \%$ to $97 \%$ data coverage. For the wet days, $\Delta \mathrm{T}$ also ranged from $-0.5{ }^{\circ} \mathrm{C}$ to $0.5{ }^{\circ} \mathrm{C}$, with $77 \%$ to $93 \%$ data coverage, for the harmonic, arctangent and logarithmic algorithms, and from $-1{ }^{\circ} \mathrm{C}$ to $1{ }^{\circ} \mathrm{C}$ with $77 \%$ to $80 \%$ data coverage for the amplitude, phase and conductionconvection algorithms.

The lower maximum absolute values of $\Delta \mathrm{T}$ (i.e., $\Delta \mathrm{T}=$ $0.5^{\circ} \mathrm{C}$ ) were generated by the harmonic, arctangent and logarithmic algorithms, as compared to other algorithms that produced $\Delta T=1{ }^{\circ} \mathrm{C}$. Furthermore, the lower data coverage obtained from the PDFs for the wet days as compared to the dry days, in addition to the information obtained from the statistical indicators in Table 3, showed that the heterogeneity induced by transient changes in $\theta$ during these wet days negatively impacted on the accuracy of all of the algorithms in the modeling of $T$, and hence on the estimation of $K_{h}$. This is an indication that higher numbers of harmonics are needed for a better representation of the wet days

The algorithms used in the present study can be divided 


\begin{tabular}{|c|c|c|c|c|c|}
\hline Algorithm & $\begin{array}{c}\text { SE } \\
\left(\mathrm{W} / \mathrm{m}^{2}\right)\end{array}$ & NSE & $\mathbf{R}^{2}$ & D & C \\
\hline \multicolumn{6}{|l|}{ Wet days } \\
\hline Harmonic & 0.32 & 0.01 & 0.987 & 0.997 & 0.99 \\
\hline Arctangent & 0.47 & 0.02 & 0.971 & 0.993 & 0.978 \\
\hline Logarithmic & 0.53 & 0.02 & 0.963 & 0.991 & 0.972 \\
\hline Amplitude & 0.87 & 0.03 & 0.898 & 0.973 & 0.922 \\
\hline Phase & 0.87 & 0.03 & 0.898 & 0.974 & 0.923 \\
\hline Conduction-convection & 0.88 & 0.03 & 0.895 & 0.973 & 0.921 \\
\hline \multicolumn{6}{|l|}{ Dry days } \\
\hline Harmonic & 0.23 & 0.01 & 0.994 & 0.999 & 0.996 \\
\hline Arctangent & 0.32 & 0.01 & 0.988 & 0.997 & 0.991 \\
\hline Logarithmic & 0.30 & 0.01 & 0.99 & 0.998 & 0.993 \\
\hline Amplitude & 0.74 & 0.02 & 0.936 & 0.984 & 0.952 \\
\hline Phase & 0.73 & 0.02 & 0.938 & 0.984 & 0.953 \\
\hline Conduction-convection & 0.74 & 0.02 & 0.936 & 0.0984 & 0.952 \\
\hline
\end{tabular}

Table 3. Results of the statistical analyses at the Ile Ife site, 2004. SE, computed standard errors of the estimates; NSE, normalized standard errors of the estimates; $\mathrm{R}^{2}$, correlation coefficient; $\mathrm{D}$, agreement index; and $\mathrm{C}$, confidence index.

\section{Conduction-convection}
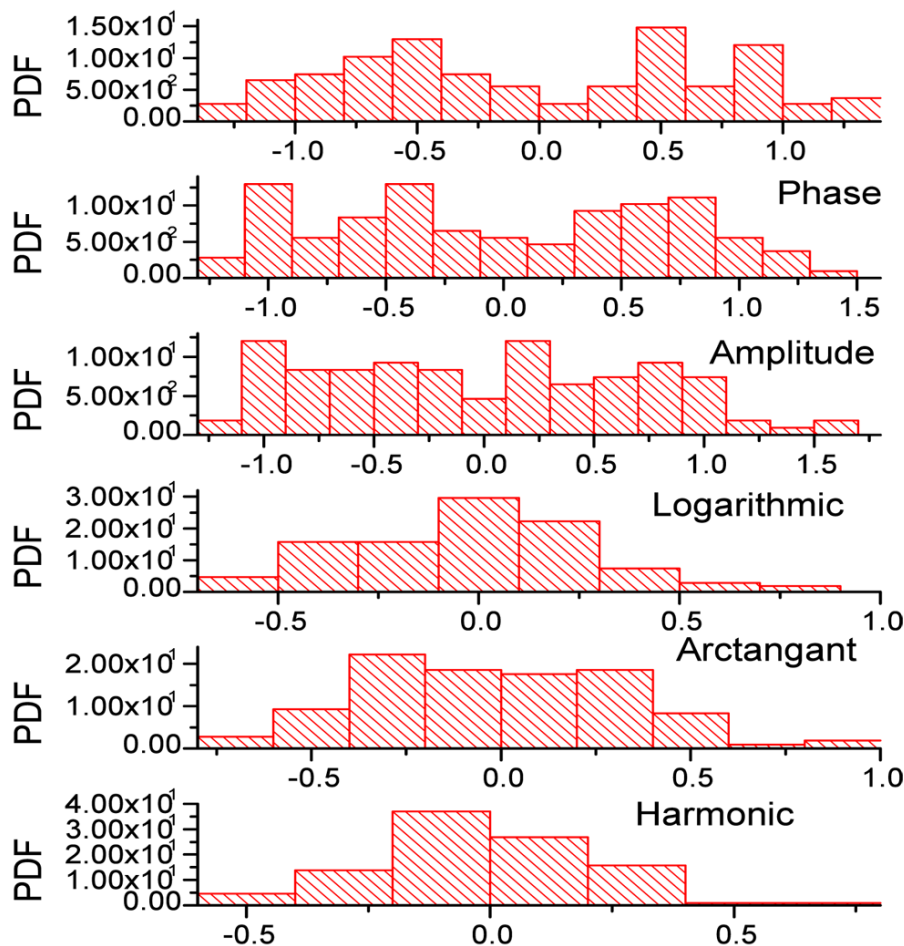

a)

Temperature difference $\left({ }^{\circ} \mathrm{C}\right)$
Conduction-convection
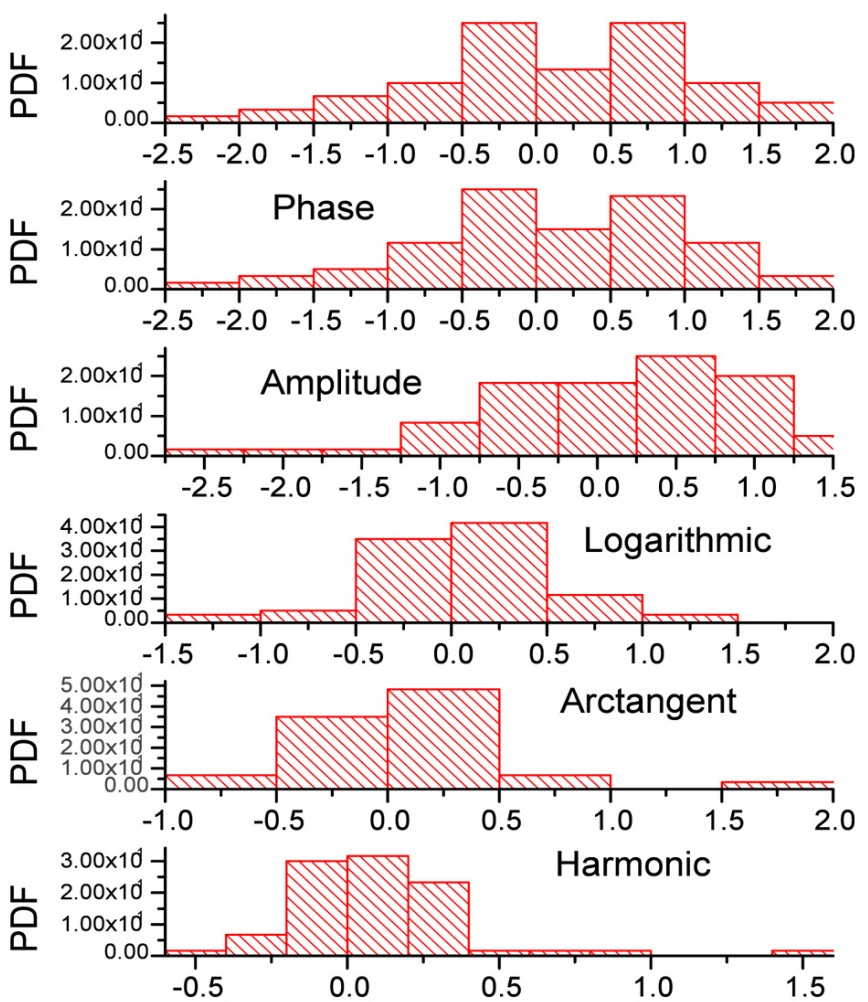

b)

Temperature difference $\left({ }^{\circ} \mathrm{C}\right)$

Figure 5. (a) Empirical probability distribution function, PDF, of subtraction between the temperature predicted by harmonic, arctangent, logarithmic, phase, amplitude and conduction-convection algorithm for the soil layer ranging from $0.05 \mathrm{~m}$ to $0.01 \mathrm{~m}$ with the soil temperature at $0.10 \mathrm{~m}$ depth from DOY 55 and DOY 61 to DOY 68 (dry days), 2004. (b) Empirical probability distribution function, PDF, of subtraction between the temperature predicted by harmonic, arctangent, logarithmic, phase, amplitude and conduction-convection algorithm for the soil layer ranging from $0.05 \mathrm{~m}$ to $0.01 \mathrm{~m}$ with the soil temperature at $0.10 \mathrm{~m}$ depth from DOY 55 and DOY 61 to DOY 68 (wet days), 2004. 
into two broad groups: those that require a single sinusoidal wave to model $T$ in one group, and those that require two or more sinusoidal waves to model $T$ in another group. The amplitude, phase and conduction-convection algorithms belong to the first group, while the harmonic, arctangent and logarithmic algorithms belong to the second group. The values of the statistical indices SE, NSE, $\mathrm{R}^{2}, \mathrm{D}$ and $\mathrm{C}$ obtained for each of the groups are within similar ranges and are not significantly different (see Table 3). This suggested that the differences between the groups might be due to the omission or inclusion of the same physical parameter.

The number of the harmonics used for the modeling of $T$ for each group is one probable reason for this difference. The higher the numbers of the harmonics, the more realistic is the predicted $T$ (the harmonic algorithm that uses highest number of harmonics gave the best performance, as indicated by the statistical indices). The worst model of $T$ was obtained from those algorithms that were based on a single harmonic (see Table 3).

The conduction-convection algorithm is based on the assumptions that the heterogeneity in the soil layer is only due to the flux of moisture, and is not due to changes in the soil texture, and that the diurnal variation of $T$ in each layer of the soil follows a single sinusoidal curve. According to Yang and Wang [2008], these assumptions induce significant errors, because they are either far from reality or are difficult for practical application. In the present study, efforts were made to reduce the assumptions to only one, by using a soil layer of a shallow depth (i.e., $0.10 \mathrm{~m}$ ), where the soil texture was uniform with depth. In spite of this, the requirement for multiple harmonics to model $T$ accurately appeared to supersede whatever contribution the convection process made at this site. The conduction-convection algorithm, however, predicted the temperature amplitude better than the phase algorithm, which also used only one harmonic to model $T$ (see Figure 4a, b).

\subsubsection{The Ibadan site}

The smallest value of $K_{h}$ was $3.64 \times 10^{-7} \mathrm{~m}^{2} \mathrm{~s}^{-1}$, and this was obtained from the conduction-convection algorithm on DOY 165. The maximum value was $2.23 \times 10^{-6} \mathrm{~m}^{2} \mathrm{~s}^{-1}$, and this was obtained from the arctangent algorithm on DOY 154. The maximum, minimum and mean values of $K_{h}$ calculated by the six algorithms are presented in Table 1 .

The values of parameter $w$ from the conduction-convection algorithm as calculated from Equation (13) are given in Table 4. These show that there was percolation of water into the sub-surface on DOY 155, DOY 157, DOY 159, DOY 163 and DOY 165. The magnitude of the net water fluxes into the subsurface was high for the days when there was rain and for the days immediately afterwards.

The measured and predicted soil temperatures at 0.10 $m$ depth for a dry day (DOY 155) and a wet day (DOY 166)

\begin{tabular}{cc}
\hline DOY & $\begin{array}{c}w \\
\left(\times 10^{6} \mathrm{~m} / \mathrm{s}\right)\end{array}$ \\
\hline 154 & 7.10 \\
155 & -1.00 \\
156 & 1.60 \\
157 & -0.02 \\
158 & 3.49 \\
159 & -0.55 \\
161 & 1.53 \\
162 & 1.29 \\
163 & -0.57 \\
164 & 0.06 \\
165 & -10.00 \\
166 & 3.00 \\
\hline
\end{tabular}

Table 4. The values of $w$ calculated by the conduction-convection algorithm for the soil layer of $0.05 \mathrm{~m}$ to $0.10 \mathrm{~m}$ at the Ibadan site from DOY 154 to DOY166, 2006.

are presented in Figure 6a, b. It can be seen that the measured temperature was best fitted with the harmonic, arctangent and logarithmic algorithms, as these generated larger coefficients of determination $\left(R^{2}\right)$, agreement indices $(D)$ and confidence indices $(\mathrm{C})$ than the other three algorithms (Table 5). Together with the SE and NSE, these statistical indices are presented in Table 5 for the wet days (i.e., DOYs 161 to 166) and the dry days (i.e., DOYs 154 to159). The harmonic algorithm had the lowest SE and NSE. The arctangent and logarithmic algorithms had the second and third lowest values of the SE and NSE. Thus, the amplitude, phase and conductionconvection algorithms that used one sinusoidal curve in this modeling approach gave comparatively less accurate descriptions of $T$. This is consistent with the results obtained at the Ile Ife site. The results for the evaluations of the algorithms obtained at this site were comparable to those obtained at the Ile Ife site, in spite of the seasonal variations, as indicated by the differences in $\theta$ at the two sites and the times of $T$ maximum for each day (see Figures 4, 6).

\subsection{Influence of soil moisture content on estimation of soil} thermal diffusivity

The period of measurements at the two sites were selected to obtain a wide spectrum of $\theta$. By keeping other factors, such as soil type or texture, and vegetation cover, constant, the thermal diffusivity $K_{h}$ was expected to vary only with $\theta$. Comparisons of the mean, maximum and minimum values of $K_{h}$ at the two sites show that these parameters were higher at Ibadan, where $\theta$ was also higher (Table 1). The datasets from the two sites were combined to investigate this variation. All of the six algorithms show increasing trends for the variations in $K_{h}$ with $\theta$ (Figure $7 \mathrm{a}, \mathrm{b}$ ). The trend lines were 

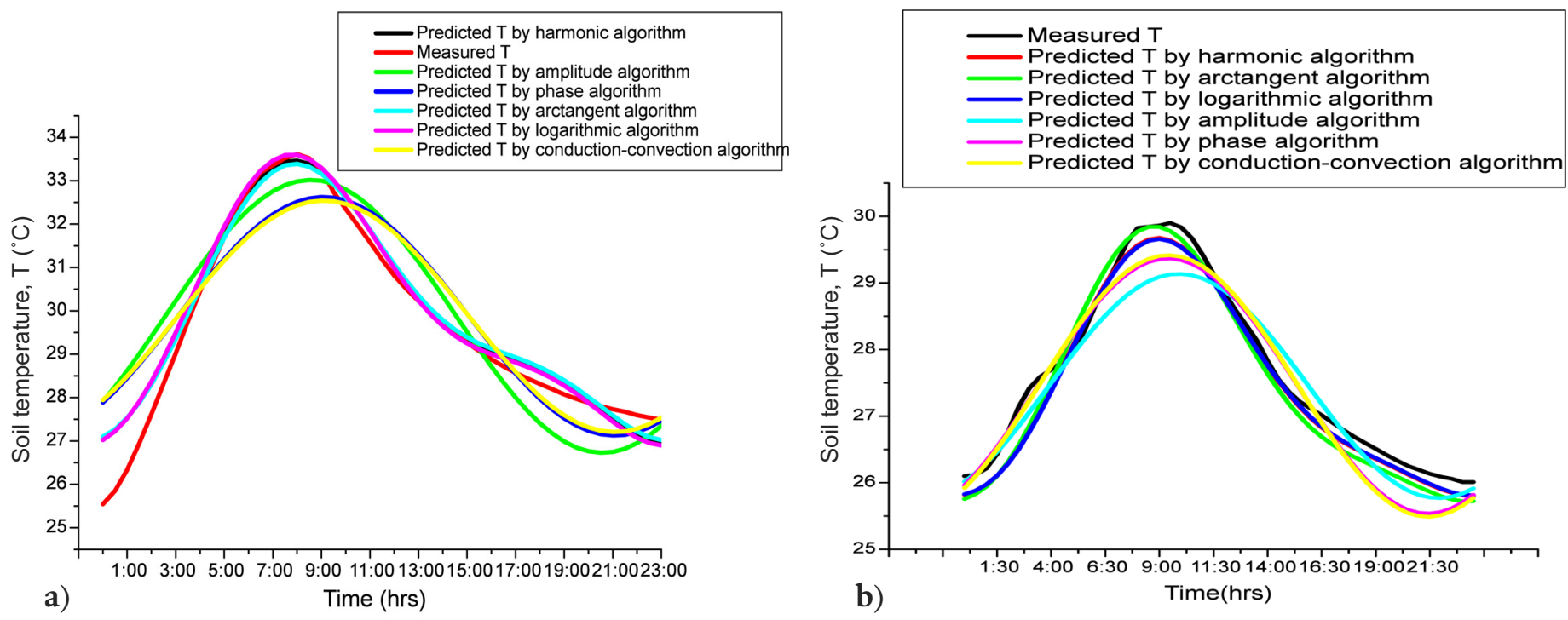

Figure 6. (a) Comparisons of soil temperature predicted by harmonic, arctangent, logarithmic, phase, amplitude and conduction-convection algorithm against measurements of soil temperature at $0.01 \mathrm{~m}$ depth at Ibadan site on DOY 155, 2006. (b) Comparisons of soil temperature predicted by harmonic, arctangent, logarithmic, phase, amplitude and conduction-convection algorithm against measurements of soil temperature at $0.01 \mathrm{~m}$ depth at Ibadan site on DOY 166, 2006.

\begin{tabular}{|c|c|c|c|c|c|}
\hline Type of algorithm & $\begin{array}{c}\text { SE } \\
\left(\mathrm{W} / \mathrm{m}^{2}\right)\end{array}$ & NSE & $\mathbf{R}^{2}$ & $\mathbf{D}$ & C \\
\hline \multicolumn{6}{|l|}{ Wet days } \\
\hline Harmonic & 0.36 & 0.01 & 0.977 & 0.994 & 0.983 \\
\hline Arctangent & 0.39 & 0.01 & 0.974 & 0.993 & 0.980 \\
\hline Logarithmic & 0.39 & 0.01 & 0.974 & 0.993 & 0.980 \\
\hline amplitude & 0.70 & 0.02 & 0.897 & 0.976 & 0.924 \\
\hline Phase & 0.68 & 0.02 & 0.909 & 0.978 & 0.932 \\
\hline Conduction-convection & 0.79 & 0.03 & 0.869 & 0.969 & 0.903 \\
\hline \multicolumn{6}{|l|}{ Dry days } \\
\hline Harmonic & 0.31 & 0.01 & 0.982 & 0.997 & 0.987 \\
\hline Arctangent & 0.33 & 0.01 & 0.980 & 0.995 & 0.985 \\
\hline Logarithmic & 0.32 & 0.01 & 0.981 & 0.995 & 0.986 \\
\hline amplitude & 0.72 & 0.02 & 0.905 & 0.976 & 0.929 \\
\hline Phase & 0.70 & 0.02 & 0.909 & 0.977 & 0.931 \\
\hline Conduction-convection & 0.80 & 0.03 & 0.881 & 0.972 & 0.913 \\
\hline
\end{tabular}

Table 5. Results of the statistical analyses at the Ibadan site, 2006. SE, computed standard errors of the estimates; NSE, normalized standard errors of the estimates; $\mathrm{R}^{2}$, correlation coefficient; $\mathrm{D}$, agreement index; and $\mathrm{C}$, confidence index.

almost identical for the phase algorithm $\left(R^{2}=0.47\right)$ and the conduction-convection algorithm $\left(\mathrm{R}^{2}=0.47\right)$. The phase and conduction-convection algorithms are both based on the phase differences between the temperature wave amplitudes at the two soil depths, and they therefore produced similar courses of variation with $\theta$. The amplitude trend line $\left(\mathrm{R}^{2}=\right.$ 0.36) was almost parallel with those of the phase and conduction-convection algorithms (Figure $7 \mathrm{~b}$ ). This might be an indication of the single sinusoidal temperature wave representation of these three algorithms. The coefficient of deter- mination, $\mathrm{R}^{2}$, for the arctangent, logarithmic and harmonic algorithms were $0.49,0.50$ and 0.70 , respectively.

\section{Conclusions}

This study aimed at obtaining a more accurate representation of the soil thermal dynamics in meteorological and hydrological models for the region of study, by investigating the effects of seasonal and transient variations in soil moisture content $(\theta)$ on the thermal diffusivity, $K_{h}$, with a view to establishing an empirical relationship between the 

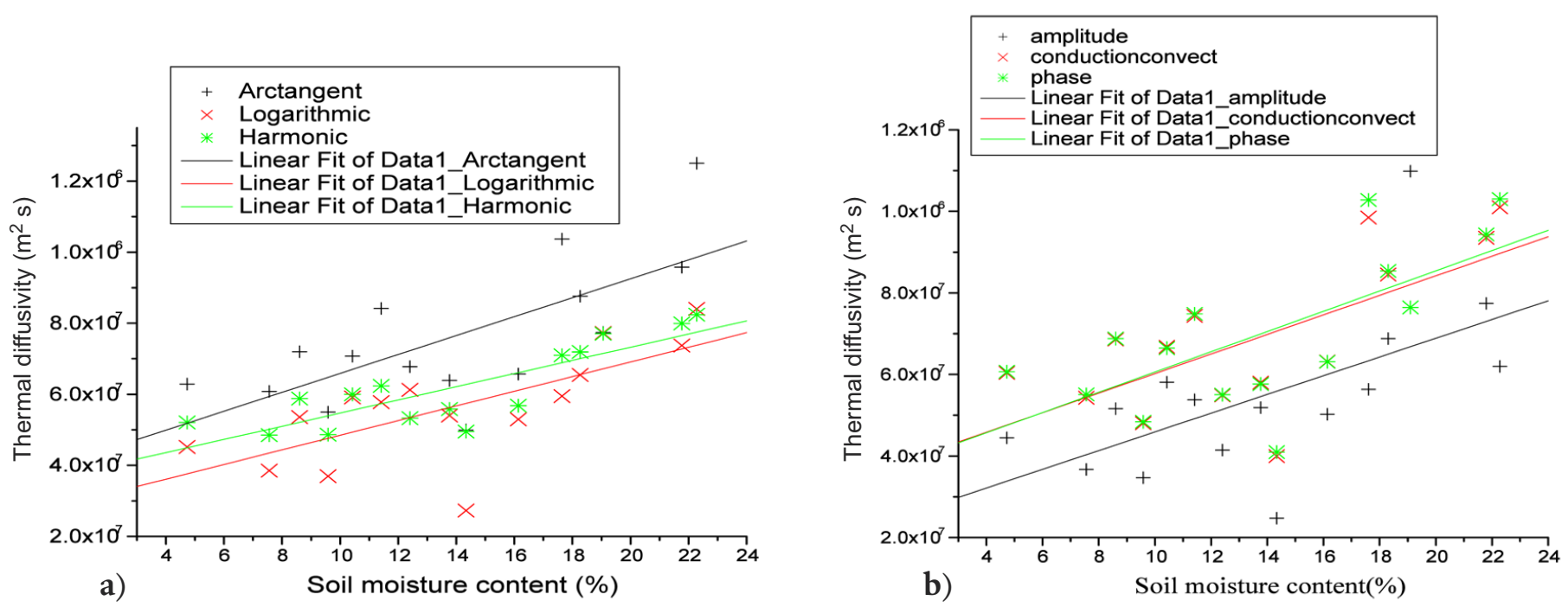

Figure 7. Variation of soil thermal diffusivity $k_{h}\left(\mathrm{~m}^{2} \mathrm{~s}^{-1}\right)$ with volumetric soil water content $\theta(\%)$ (a) for harmonic, arctangent and logarithmic algorithms, (b) for amplitude, phase and conduction-convection algorithms.

two parameters, and by also evaluating six thermal diffusivity algorithms to determine those that are appropriate for the region of study.

The present study shows that $K_{h}$ has an increasing trend with increasing $\theta$. All of the statistical indices used show that the transient heterogeneity that was induced by the rainfall affected the accuracy of all of these algorithms. The conduction-convection algorithm almost circumvented this problem by incorporating the heat transfer by convection process into the soil with the conduction process. The conduction-convection algorithm, however, gave comparative less accurate descriptions of the top-soil temperature with time at these sites, because of the assumption of a single sinusoidal curve in its modeling of the soil temperature.

Out of the six algorithms used in the present study, the harmonic, arctangent and logarithmic algorithms gave better estimates of $K_{h}$ for the region of study. These three algorithms, which are based on the convectional one-dimensional heat conduction equation, gave better descriptions of the top-soil temperatures with time than the other algorithms. The arctangent and logarithmic algorithms, which are simpler compared to the harmonic algorithm in terms of the computational requirements, can be used for this region of study.

Acknowledgements. The authors acknowledge the Nigerian Micrometeorological Experiment research group for making this study possible, and the ISP, Uppsala University, Sweden, for the equipment used during the study. The Nigerian Meteorological Agency is also acknowledged for the data used in the climatological analysis.

\section{References}

Adedokun, J.A. (1978). West African precipitation and dominant atmospheric mechanisms, Arch. Met. Geophys.

Biokl. Ser. A, 27, 289-310.

Boden, A.G. (1994). Bodenkundliche Kartieranleitung, 4.
Aufl. E. Schweizerbart'sche Verlagsbuchhandlung, Hannover, $392 \mathrm{pp}$.

Camargo, A.P., and P.C Sentelhas (1997). Performance evaluation of potential evapotranspiration estimating methods in the state of Sao Paulo, Brazil, Rev. Braz. Agrometeor., 5, 89-97.

Caslaw, H.S., and J.C. Jaeger (1959).Conduction of Heat in Solids, Clarendon Press, Oxford.

Essenwanger, O.M. (2003). Classification of Climates, Amsterdam, Elsevier.

Foken, T. (2008). Micrometeorology, Springer-Verlag Berlin Heidelberg, 306 pp.

Gao, Z., X. Fan and L. Bian (2003). An analytical solution to one-dimensional thermal conduction-convection in soil, Soil Sci., 168, 99-107.

Gao, Z, L. Wang and R. Horton (2007). Determination of soil temperature in an arid region, J. Arid Environ., 71, 157-168.

Gao, Z., D.H. Lenschow, R. Holton, M. Zhou, L. Wang and J. Wen (2008). Comparison of two soil temperature algorithms for a bare ground site on the Loess Plateau in China, J. Geophys. Res., 113; doi:10.1029/2008JD010285.

Horton, R., P.J. Wierenga and D.R Nielsen (1983). Evaluation of methods for determination of apparent thermal diffusivity of soil near the surface, Soil Sci. Soc. Am. J., 47, 23-32.

Jegede, O.O., M. Mauder, E.C. Okogbue., T. Foken., E.E. Balogun, J.A. Adedokun, E.O. Oladiran, J.A. Omotosho, A.A. Balogun, O.R. Oladosu, L.A. Sumonu, M.A. Ayoola, T.O. Aregbesola, E.O. Ogolo, E.F. Nymphas, M.O. Adeniyi, G.I. Olatona, K.O. Lapido, S.I. Ohamobi, E.O. Gbobaniyi and G.O. Akinlade (2004). The Nigerian Micrometeorological Experiment (NIMEX): An overview, J. Sci., 6, 191-202.

Mauder, M., O.O. Jegede, E.C. Okogbue, F. Wimmer and T. 
Foken (2007). Surface energy balance measurements at a tropical site in West Africa during the transition from dry to wet season, Theor. Appl. Climatol., 88, 171-183.

Nerpin, S.V., and A.F. Chudnovskil (1967). Physics of the soil, Isreal program for scientific translations, Keter Press, Jerusalem, 194-233.

Nicholson, S.E. (2001). Climatic and environmental change in Africa during the last two centuries, Climate Research, 17, 123-144.

Oke, T.R. (1978). Boundary Layer Climate, Methuen and Co., USA.

Otunla, T.A., E.O. Oladiran and M.O. Adeniyi (2008). Climatic variability and probabilistic extremes of some climatic elements over Ibadan, Online J. Earth Sci., 2, 124-129.

Seemann, J. (1979). Measurement Technology, Agrometeorology, Springer-Verlag, Berlin, 40-45.

Sellers, W.D. (1965). Physical Climatology, University of Chicago Press.

Steiner, A.L., J.S. Pal, S.A. Rauscher, J.L. Bell, N.S. Diffenbaugh, A. Boone, L.C. Sloan and F. Giorgi (2009). Land surface coupling in regional climate simulations of the West African monsoon, Clim. Dynam.; doi: 10.1007/ s003 82-009-0543-6.

Stensrud, D.J. (2007). Parameterization Schemes: Keys to Understand Numerical Weather Prediction Models, Cambridge University Press.

Taylor, J.R. (1982). An Introduction to Error Analysis: the Study of Uncertainties in Physical Measurements, Oxford University Press.

Taylor, C.M., D.J. Parker, N. Kalthoff, M.A. Gaertner, N. Philippon, S. Bastin, P.P. Harris, A. Boone, F. Guichard, A. Agusti-Panareda, M. Baldi, P. Cerlini, L. Descroix, H. Douville, C. Flamant, J.-Y. Grandpeix, and J. Polcher (2011). New perspectives on land-atmosphere feedbacks from the African Monsoon Multidisciplinary Analysis, Atmosph. Sci. Lett., 12, 38-44; doi:10.1002/asl.336.

Van Wijk, W.R., and D.A. De Vries (1963). Periodic temperature variations in a homogeneous soil, In: Physics of Plant Environment, edited by W.R. Van Wijk, Amsterdam, 103-143.

Verhoef, A, B.J.J.M. Van den Hurk, A.F.M. Jacobs and B.G. Heusinkveld (1996). The thermal soil properties for vineyard (EFEDA-I) and savanna (HAPEX-Sahel) sites, Agric. For. Meteorol., 78, 1-18.

Verhoef, A. (2004). Remote estimation of thermal inertia and soil heat flux for bare soil, Agric. For. Meteorol., 123, 221236.

Willmott, C.J, S.G. Ackleson, R.E. Davis, J.J. Feddema, K.M. Klink, D.R. Legates, J. O'Donnel and C.M. Rowe (1985). Statistics for the evaluation and comparison of models, J. Geophys. Res., 90, 8995-9005.

Yang, K., and J. Wang (2008). A temperature-prediction- correction method for estimating surface soil heat flux from soil temperature and moisture data, Sci. China Ser. D. Earth Sci., 51, 721-729.

Zhang, T., and T.E. Osterkamp (1995). Considerations in determining thermal diffusivity from temperature time series using finite difference methods, Cold Reg. Sci. Technol., 23, 333-341.

\footnotetext{
*Corresponding author: Taofeek Abiodun Otunla, University of Ibadan, Department of Physics, Ibadan, Nigeria; email: ta.otunla@mail.ui.edu.ng; biodunotunla@yahoo.com.

(C) 2013 by the Istituto Nazionale di Geofisica e Vulcanologia. All rights reserved.
} 